Scientific Review - Engineering and Environmental Sciences (2021), 30 (1), 62-74

Sci. Rev. Eng. Env. Sci. (2021), 30 (1)

Przegląd Naukowy - Inżynieria i Kształtowanie Środowiska (2021), 30 (1), 62-74

Prz. Nauk. Inż. Kszt. Środ. (2021), 30 (1)

http://iks.pn.sggw.pl

DOI 10.22630/PNIKS.2021.30.1.6

\author{
Hassnen JAFER ${ }^{1}$, Ibtehaj JAWAD ${ }^{1}$, Zaid MAJEED ${ }^{1}$, Ali SHUBBAR ${ }^{2}$ \\ ${ }^{1}$ University of Babylon, College of Engineering \\ ${ }^{2}$ Liverpool John Moores University, Department of Civil Engineering
}

\title{
The development of an ecofriendly binder containing high volume of cement replacement by incorporating two by-product materials for the use in soil stabilization
}

Key words: soil stabilization, eco-friendly binder, ordinary Portland cement, ground granulated blast furnace slag, cement kiln dust, cement replacement

\section{Introduction}

The use of cement, in the treatment of weak soils, induces chemical reactions that improve the geomechnical properties of the treated soils significantly. Hence it has been widely used for soil stabilization. It can be utilized for the stabilization of any type of soil apart from those with $\mathrm{pH}$ values less that 5.3 or organic contents of more than 2\% (Saride, Puppala \& Chikyala, 2013; Ma, Chen \& Chen, 2016). The demand for ordinary Portland cement (OPC) is increasing on a daily bases because of the industrialization and urbanization. Consequently, the cement industry has grown significantly in recent years. It has been reported by van Ruijven et al. (2016) that the global cement production is predicted to grow annually by $5 \%$. However, the OPC manufacturing have several environmental issues particularly the carbon dioxide $\left(\mathrm{CO}_{2}\right)$ emission and intensive energy consumption (Jafer, Atherton, Sadique, Ruddock \& Loffill, 2018a).

Worldwide nowadays, the global warming as well as the climate changes represent a major concern to the mankind. These phenomenon are related to the green-house gases produced by different sectors of industry which their increased emissions adversely impacting the environment. The carbon dioxide represents one of the main gases contributing to the harmful gasses, being normally emitted by the process of incineration from various industrial factories (Hermawan, Marzuki, Abduh \& Driejana, 2015). Meanwhile, the manufacturing of cement is a major sector of industry contributing 
to the emission of carbon dioxide, with a global $\mathrm{CO}_{2}$ emission of 7-9\% (Zain$\mathrm{ab}$, Zainab, Jafer, Dulaimi \& Atherton, 2018). Hence, to minimize the environmental influences of cement, researches have investigated the possibilities of utilizing new materials as alternative to cement. These materials substitute cement partially or totally to make binders used in various construction sectors such as mortars, concrete and soil stabilization (Jafer, Atherton, Ruddock \& Loffill, 2017; Jafer, Atherton, Sadique, Ruddock \& Loffill, 2018b; Majdi et al., 2020).

Supplementary cementitous materials (SCMs) are the named given to these materials that are wastes or by-products incorporated partially as cement substituents. Supplementary cementitous materials have been utilized since approximate 300 years before century in Roma when volcanic ash was incorporated with lime in building roads (Aïtcin, 2016). Supplementary cementitous materials either induce pozzolanic activity due to having a significant amount of silica such as palm oil fly ash (POFA), rice husk ash (RHA), and fly ash (FA) (Aprianti, 2017), or possess considerable contents of calcium oxide to work like cement while being blended with water such as ground granulated blast furnace slag (GGBFS), sewage sludge ash (SSA) and cement kiln dust (CKD) (Majdi et al., 2020).

Ground granulated blast furnace slag (GGBFS) is a by-product produced from the manufacturing processes of iron industry. In terms of the chemical compositions, GGBFS has chemical oxides such as lime, aluminates and silicates similar to those available in the Portland cement but in different proportions (Oner \& Akyuz, 2007). It was reported that most of mineral phases of GGBFS are in the glass phases making them easy to react with water during the hydration process (Zhao, Wang, Yan, Zhao \& Zhang, 2016). Despite of that GGBFS was highly utilized in soil stabilization. It was confirmed by previous research that GGBFS in its own have low cementitous reactivity. Hence, lime or OPC are mixed with GGBFS in order to accelerate the hydration of GGBFS via activation that involves supplying enough alkalinity (Higgins, 2005).

Cement kiln dust (CKD) is produced as a by-product during cement manufacturing retrained in the incineration gasses transferred via the kiln. The chemical composition of CKD consists primary of non-calcined and calcined raw and feed materials used in the processes of cement manufacturing in addition to fine clinker and rich alkali compositions (Kunal, Siddique \& Rajor, 2014). In spite of the fact that the CKD resulted from cement industry has been lowered subs-considered due to the utilization of new advanced methods in cement manufacture, the discard of CKD is a considerable issues in term of environmental and economic aspects in cement industry (Wild, Kinuthia, Robinson \& Humphreys, 1996).

Based on the literatures, there is a limited number of researches investigated the effect of cement replacement using binary blending of GGBFS and $\mathrm{CKD}$ on the performance of the produced binders, particularly for the use in fine grained soil stabilization. In this research, GGBFS and CKD were incorporated as replacements to the conventional binder (OPC). Hence, the OPC was replaced at different levels: 15,30 , 45, 60 and 75\%. The Atterberg limits, 
compaction parameters, and unconfined compressive strength (UCS) tests were employed to evaluate the produced mixtures and compare to the reference mixture (soil - 100\% OPC binder). To understand the improvement gained in different soil geotechnical properties, the scanning electron microscopy (SEM) technique was utilized by examining the microstructure of the paste of the most logical mixture that exhibited a closed performance to the reference binder.

\section{Materials and methods}

\section{Soil samples}

The soil samples were obtained from the main campus of University of Babylon, Babylon, Iraq. They were collected from a depth of about $0.5 \mathrm{~m}$ below natural ground surface. The particle size distribution curve obtained from carrying out both sieve and hydrometer analysis is shown in Figure 1. This curve shows that the main fraction of the soil is clay while; the silt falls in the second order. Table 1 recapitulates some geotechnical properties of the soil, while the soil micrograph image obtained from the SEM test. It appeared as flocks and platy shape particles reflecting the existance of clay minerals.

TABLE 1. Some geotechnical properties of the soil

\begin{tabular}{|l|c|c|}
\hline Property & Unit & Value \\
\hline Liquid limit $(L L)$ & $\%$ & 42 \\
\hline Plastic limit $(P L)$ & $\%$ & 21.5 \\
\hline Plasticity index $(P I)$ & - & 20.5 \\
\hline Sand & $\%$ & 11 \\
\hline Silt & $\%$ & 41 \\
\hline Clay & $\%$ & 48 \\
\hline Specific gravity $\left(\mathrm{G}_{\mathrm{s}}\right)$ & - & 2.66 \\
\hline $\begin{array}{l}\text { Maximum dry density } \\
(M D D)\end{array}$ & $\mathrm{Mg} \cdot \mathrm{m}^{-3}$ & 1.61 \\
\hline $\begin{array}{l}\text { Optimum moisture content } \\
(O M C)\end{array}$ & $\%$ & 21.5 \\
\hline $\begin{array}{l}\text { Unconfined compressive } \\
\text { strength }(U C S)\end{array}$ & $\mathrm{kPa}$ & 144 \\
\hline
\end{tabular}

\section{Binder materials}

The materials used to produce the binders were: OPC which was obtained from a local factory located in Babylon

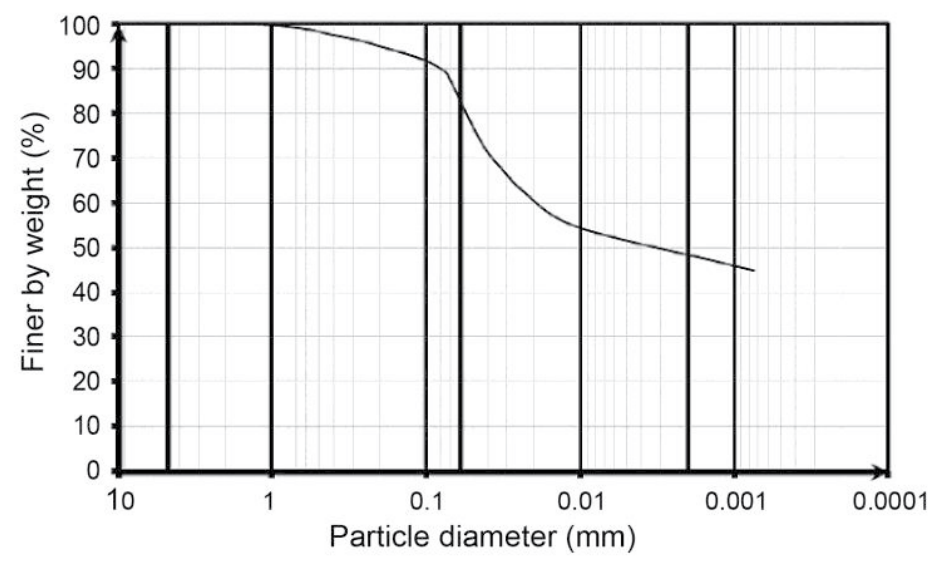

FIGURE 1. Grain size distribution curve for obtained soil 
Province, Iraq, ground granulated blast furnace slag (GGBFS); supplied from Hanson Heidelberg Cement Group, Skuthorpe, UK, and cement kiln dust (CKD) which was provided by local cement factory.

The chemical compositions of the candidate materials are listed in Table 2. These compositions were obtained by conducting X-ray fluorescence (XRF) analysis using Shimadzu's EDX-720 Energy Dispersive X-Ray Fluorescence Spectrometer. It is important to observe that the percentages of calcium oxide $\mathrm{CaO}$ in GGBFS and CKD were more than $42 \%$ and $57 \%$ respectively, which are considerable values for the desired objective. On the other hand, the content of silica oxide $\left(\mathrm{SiO}_{2}\right)$ available in the composition of GGBFS was high enough to be an alternative pozzolanic source of the replaced cement. In the same view, the source of alumina $\left(\mathrm{Al}_{2} \mathrm{O}_{3}\right)$ provided by GGBFS and CKD surpassed that available in cement.

Figure 2 presents the SEM images of binder materials along with virgin soil in their powder states. The EDX Oxford In-

TABLE 2. The major chemical compositions of the candidate materials

\begin{tabular}{|c|c|c|c|}
\hline Item & OPC & GGBFS & CKD \\
\hline $\mathrm{CaO}[\%]$ & 65.89 & 42.27 & 57.23 \\
\hline $\mathrm{SiO}_{2}[\%]$ & 24.71 & 41.29 & 16.52 \\
\hline $\mathrm{Al}_{2} \mathrm{O}_{3}[\%]$ & 1.71 & 5.14 & 4.2 \\
\hline $\mathrm{Fe}_{2} \mathrm{O}_{3}[\%]$ & 1.61 & - & 3.8 \\
\hline $\mathrm{MgO}[\%]$ & 1.32 & 4.06 & 0.8 \\
\hline $\mathrm{Na}_{2} \mathrm{O}[\%]$ & 1.36 & 3.13 & 0.23 \\
\hline $\mathrm{K}_{2} \mathrm{O}[\%]$ & 0.83 & 0.72 & 6.72 \\
\hline $\mathrm{SO}_{3}[\%]$ & 2.54 & 1.29 & 4.31 \\
\hline $\mathrm{TiO}_{2}[\%]$ & - & 1.01 & 0.21 \\
\hline $\mathrm{pH}[-]$ & 12.93 & 11.65 & 12.75 \\
\hline
\end{tabular}

ca $\mathrm{x}$-act detector and FEI SEM models Inspect $S$ instrument was employed for SEM imaging using voltages acceleration of 5-20 kV. For utmost image clarity, a sputter cater was used to coat the specimen by palladium thin layer. It can be seen that the GGBFS appeared as irregular shapes, while CKD shows agglomerated particles. An instrument used laser particle size analyzer was employed to disclose the gradation of binder materials. The grain size distribution curves of OPC and the replacement materials used are illustrated in Figure 3. It can be perceived that GGBFS is finer than the OPC which gave an opportunity to make the chemical reaction faster and more reactive.

\section{Laboratory program}

The laboratory program involved three main stages: The untreated soil classification experiments in addition, the unconfined compression test (UCS) were carried out in the first stage. The second stage included the process of preparing the specimens of the soil treated with different binder mixtures contained OPC, GGBFS, and CKD with different proportions as illustarted in Table 3 . At this stage, Atterberg limits, compaction parameters, and UCS test were conducted. In all complementary mixtures, the strategy of replacement comprised using GGBFS of two folds of CKD so that the total replacement began with $15 \%$ from the total OPC. Then, the $15 \%$ was increased to be $30,45,60$ and $75 \%$.

Tests of Atterberg limits were made according to standard BS 1377-2:1990 (British Standard Institution [BSI], 1990a). The adopted procedure of standard Proctor compaction test matched with 

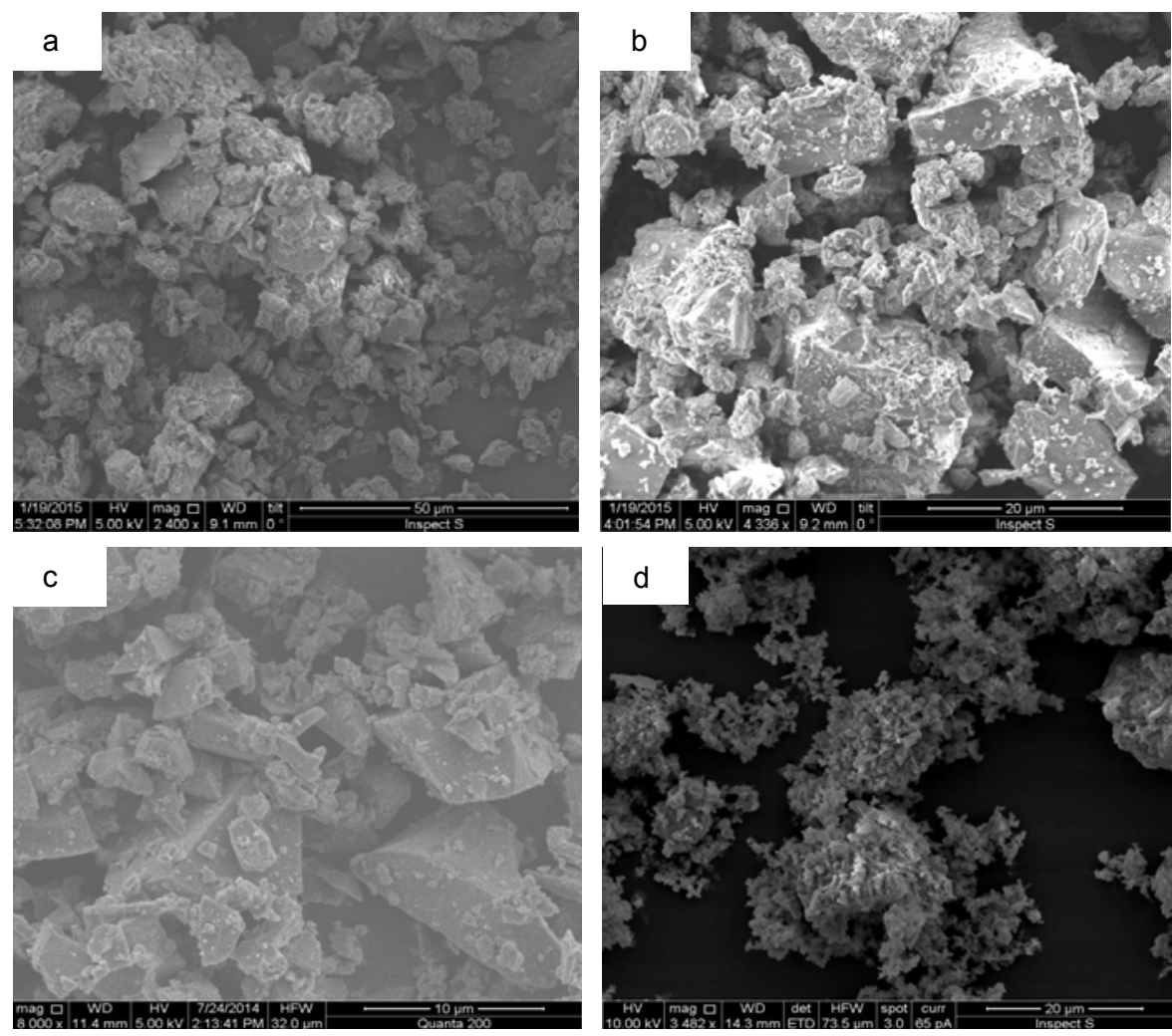

FIGURE 2. SEM magnification of (a) virgin soil, (b) OPC, (c) GGBFS and (d) CKD

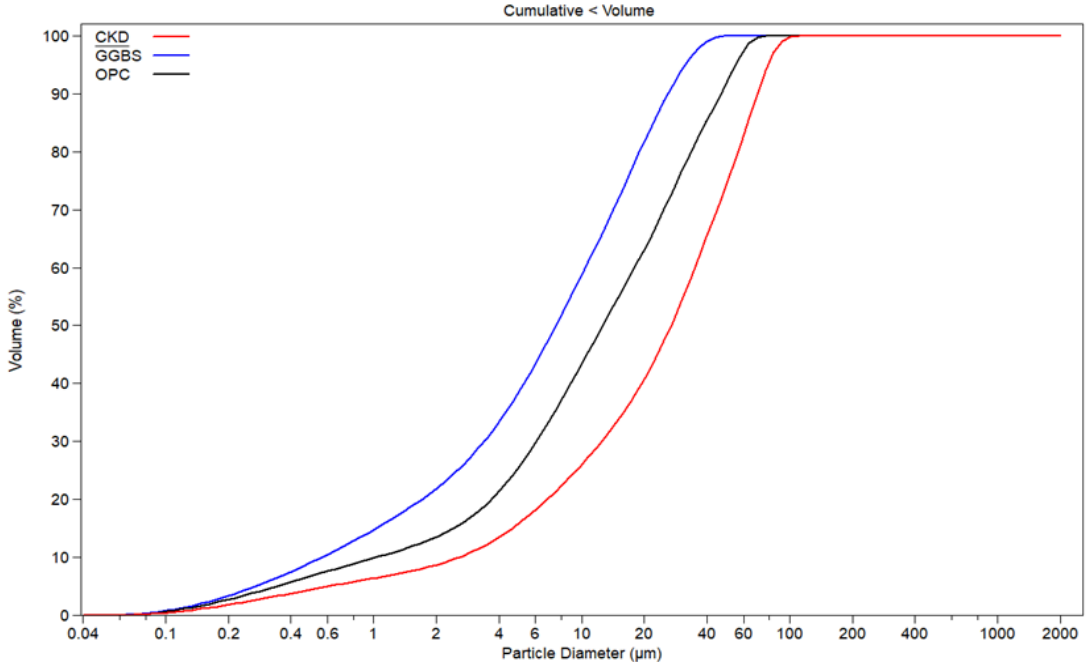

FIGURE 3. Gradations of GGBSF, CKD and OPC 
TABLE 3. Mixing procedure adopted in this project

\begin{tabular}{|c|c|c|c|c|c|}
\hline \multirow{2}{*}{ No } & \multirow{2}{*}{$\begin{array}{c}\text { Replacement } \\
{[\%]}\end{array}$} & \multirow{2}{*}{ Mix. ID } & \multicolumn{3}{|c|}{ Percentages by the total binder } \\
\cline { 4 - 6 } & & & OPC & GGBFS & CKD \\
\hline 1 & 0 & US & 0 & 0 & 0 \\
\hline 2 & 0 & RF & 100 & 0 & 0 \\
\hline 3 & 15 & OGC1 & 85 & 10 & 5 \\
\hline 4 & 30 & OGC2 & 70 & 20 & 10 \\
\hline 5 & 45 & OGC3 & 55 & 30 & 15 \\
\hline 6 & 60 & OGC4 & 40 & 40 & 20 \\
\hline 7 & 75 & OGC5 & 25 & 50 & 25 \\
\hline
\end{tabular}

standard BS 1377-4 (BSI, 1990b). Strain controlled triaxial testing machine with zero lateral stress $\left(\sigma_{3}\right)$ was employed to performed UCS in which the standard BS 1377-7 (BSI, 1990c) was adopted for $U C S$ test. The samples prepared for this test were made at densities and moisture contents corresponding to maximum dry density and optimum moisture content obtained for each mixture. All specimens were prepared with dimensions of 38 and $76 \mathrm{~mm}$ in diameter and height respectivily, then wrapped by polyethylene plastic film to maintain the moisture of soil sample while stored during the curing time.

At the third stage, and to identify some mechanisms of treatment along chemical reactions took place over curing periods, a series of scanning electron magnification analyses, for specimens of the most promising binder, after each curing time was performed. Same apparatus and procedure mentioned in section 2.3 were used for this purpose.

\section{Results and discussion}

\section{Atterberg limits}

The results obtained from Atterberg limits test for the virgin soil (US) were 42, 21.5 and $20.5 \%$ for $L L, P L$, and $P I$ respectively. Since the $P I$ is greater than 17 , US is considered as a high plasticity soil. The results experienced some increase in $L L$ and $P L$ in the case of RF specimen whereas, a noticeable reduction in PI was obtained, and the PI was lowered towered $13.8 \%$. These results agreed with the previous studies (Al-Zoubi, 2008; Jafer et al., 2018b) where the increments in $L L$ and $P L$ were justified by the increase in the water demand necessary for the cement hydration. Table 4 shows the results of Atterberg limits of primary and complementary mixtures. In the view of this table, it can be inferred that partially replacement of OPC by GGBFS and CKD induced slightly increases in the values of both $L L$ and $P L$ for all mixtures tested in this study. On 
TABLE 4. Results of Atterberg limits

\begin{tabular}{|c|c|c|c|c|}
\hline No & Mix ID & $L L$ & $P L$ & $P I$ \\
\hline 1 & US & 42 & 21.5 & 20.5 \\
\hline 2 & RF & 46.8 & 33 & 13.8 \\
\hline 3 & OGC1 & 46 & 32 & 14 \\
\hline 4 & OGC2 & 46.3 & 32.7 & 13.6 \\
\hline 5 & OGC3 & 47 & 33.6 & 13.4 \\
\hline 6 & OGC4 & 47.6 & 34 & 13.6 \\
\hline 7 & OGC5 & 48.4 & 35.2 & 13.2 \\
\hline
\end{tabular}

the other hands, $P I$ values were seeing to slightly increase in the case of OGC1 and then little decrease for the other mixtures when compared with those of RF. It should be noted that the binder OGC5 indicated the lowest value of PI (13.2) among all other mixtures.

\section{Compaction parameters}

Regarding the results of compaction, the $M D D$ and $O M C$ for US were 1.61 $\mathrm{gm} \cdot \mathrm{cm}^{-3}$ and $20.5 \%$ respectively. Due to adding OPC in the case of RF mixture, a reduction took place in the value of $M D D$ to be $1.52 \mathrm{gm} \cdot \mathrm{cm}^{-3}$. Furthermore, a considerable growth in the value of $O M C$ can be observed for RF specimen which became $27 \%$. The reduction in $M D D$ is due to flocculation and agglomeration in clay particles to make them coarser leading to increase the void ratio (Hayano, Dong \& Morikawa, 2013). Moreover, the formation and crystallization of cementitious gel after a series of chemical reactions between soil minerals and OPC components formed needle structures which were in turn forms rough texture. This texture characterized by void ratio greater than that in US and less density (Hayano et al., 2013). Figure 4 presents the change in $M D D$ and $O M C$ for all studied mixtures. The results of compaction tests also indicated an increase in the $M D D$ accompanied with a reduction in the $O M C$ after the inclusion of GGBFS and CKD particularly with the use of OGC1. This could be attributed to the reduction in the water demand due to the decrease occurred in the active lime after the cement replacement as well as the high fineness of GGBFS replaced the OPC in the aforementioned

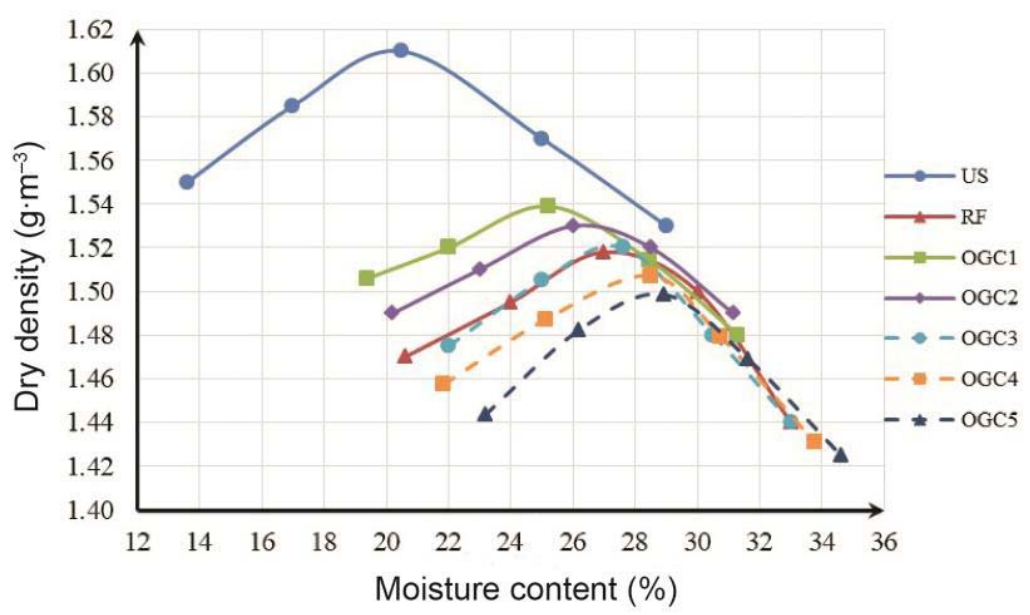

FIGURE 4. Dry densities - moisture contents for US, RF, and all complementary mixtures 
binder (Eyo, Ng'ambi \& Abbey, 2020). However, the values of $M M D$ then decreased and $O M C$ increased with the continuous increase the portion of cement replacement in the used binder as shown in Figure 4.

\section{Results of $U C S$ test}

Figure 5 illustrates the outcomes of unconfined compressive strength tests. Based on the obtained results, the strength of US specimens was $144 \mathrm{kN} \cdot \mathrm{m}^{-2}$. As per the UCS test results, the strength of treated soil after cement replacement experienced significant growth compared with the RF strength. The partial replacement of OPC using 2:1 mixing proportions of GGBFS and CKD succeed in generating the cementitious gel which plays the main role of strength evolution. This inference is clarified from Figure 5, where UCS developed generally in the same trend over curing time for the mixtures OGC1, OGC2, and OGC3. However, the strength gain demonstrat- ed lower trends in the OGC4 and OGC5 mixtures. This significant growth in the strength can be attributed to the formation of cementitious gel which bonded soil particles together in one side and crystallized more and more over time on the other side (Pourakbar, Asadi, Huat \& Fasihnikoutalab, 2015; Eyo et al., 2020). These two mechanisms make the soil strength developed over curing period.

Moreover, the strength of the first three mixtures gained at rate higher than that of the other mixtures particularly at the short and medium term curing periods. Where, the $U C S$ reached values between 1,300 and $1,281 \mathrm{kN} \cdot \mathrm{m}^{-2}$ at the age of 28 days. At the long term curing, the results hovered from 1,376 to 1,350 $\mathrm{kN} \cdot \mathrm{m}^{-2}$ at age of 90 days which almost closed to that of RF. But the results showed noticeable reduction particularly in the case OGC5 for all curing periods compared with RF strength. This is may be due to the OPC as activator became not enough for chemical reaction of GGBFS and CKD and in turns induced

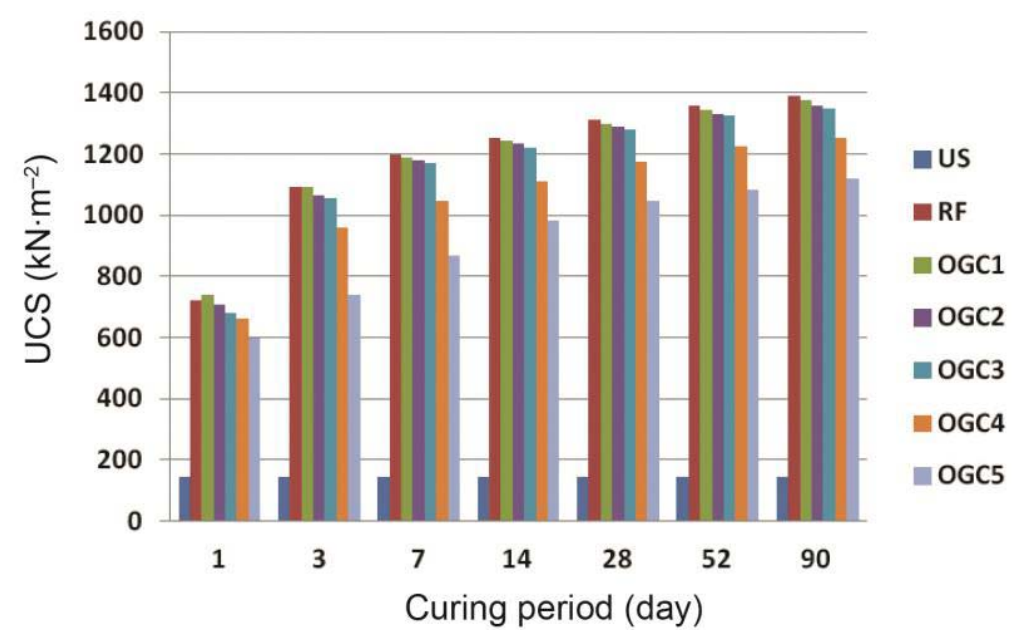

FIGURE 5. Strength developments over curing periods for all mixtures 
low creation of cementitious gel (Rahman, Abo-El-Enein, Aboul-Fetouh \& Shehata, 2016; Shubbar et al., 2020).

These results of UCS indicated that the OPC can be replaced up to $45 \%$ by GGBFS and CKD (2:1) and got almost same results of strength of the soil $-100 \%$ OPC mixture. However, the replacement of $\mathrm{OPC}$ with $60 \%$ using the combination of GGBFS and CKD (OGC4) indicated accepted results to improve most of the geotechnical properties of the stabilized soil in this study in comparison to those gained from using the binder $100 \%$ OPC. The proper percentages of calcium oxide, alumina, and silica included in the chemical composition of GGBFS and CKD gave appropriateness to partial exchange the OPC.

\section{SEM analysis results}

Figure 6 presents the results of microscopic analysis and images of SEM of $45 \%$ replacement mixture (OGC3) after 6 periods of curing; $1,3,7,28,52$, and 90 days. The analysis pursued the products of chemical reaction results over the mentioned curing periods. The reaction in the short term (in the first day up to 7 days) produced a texture of needle like shape which belongs to ettringite material. Hexagonal shape particles can be detected in the mentioned ages of reaction which were Portlandite production $(\mathrm{CH})$. In addition, at 3 and 7 days of curing, calcium silicate hydrate (C-S-H) can be observed which is the essential cementitious gel responsible for binding the soil particles to each other and strengthen the whole mass of soil. The formation of these materials reflects the reactivity of the proposed materials (CKD and GGBSF) to produce the de- sired cement characteristics (Sadique, Al-Nageim, Atherton, Seton \& Dempster, 2013). At the medium age of curing, the Ettringite and $\mathrm{CH}$ disappeared under SEM microscope which revealed that they were consumed in chemical reactions at this age to produce more $\mathrm{C}-\mathrm{S}-\mathrm{H}$ gel to be the only materials covered the scene. Similar findings were reported by Jha and Sivapullaiah (2015) and Shubbar et al. (2020). Finally, the long term aging (52 and 90 days of curing) showed that the C-S-H gel began to get high crystallization so that it became solid and very dense matrix. The formation of this dense crystal matrix explains the gain of compressive strength of soil - cement mixture along the curing periods.

\section{Conclusions}

In view of previous results, the following conclusions can be extracted:

- The plasticity index decreased significantly when adding 9.0\% OPC compared with untreated soil. Cement replacement using GGBFS and CKD as waste materials can give relatively same reduction in plasticity of soil.

- A reduction in maximum dry density and increment in optimum moisture content were experienced in the treated soil by OPC and similar trend of results was found in the mixtures where replacement was made.

- The outcomes of strength evolution showed that the strength of OGC1, OGC2, and OGC3 mixtures gained at a rate higher than that of OGC4 and OGC5 particularly at the short and medium term of curing periods. 

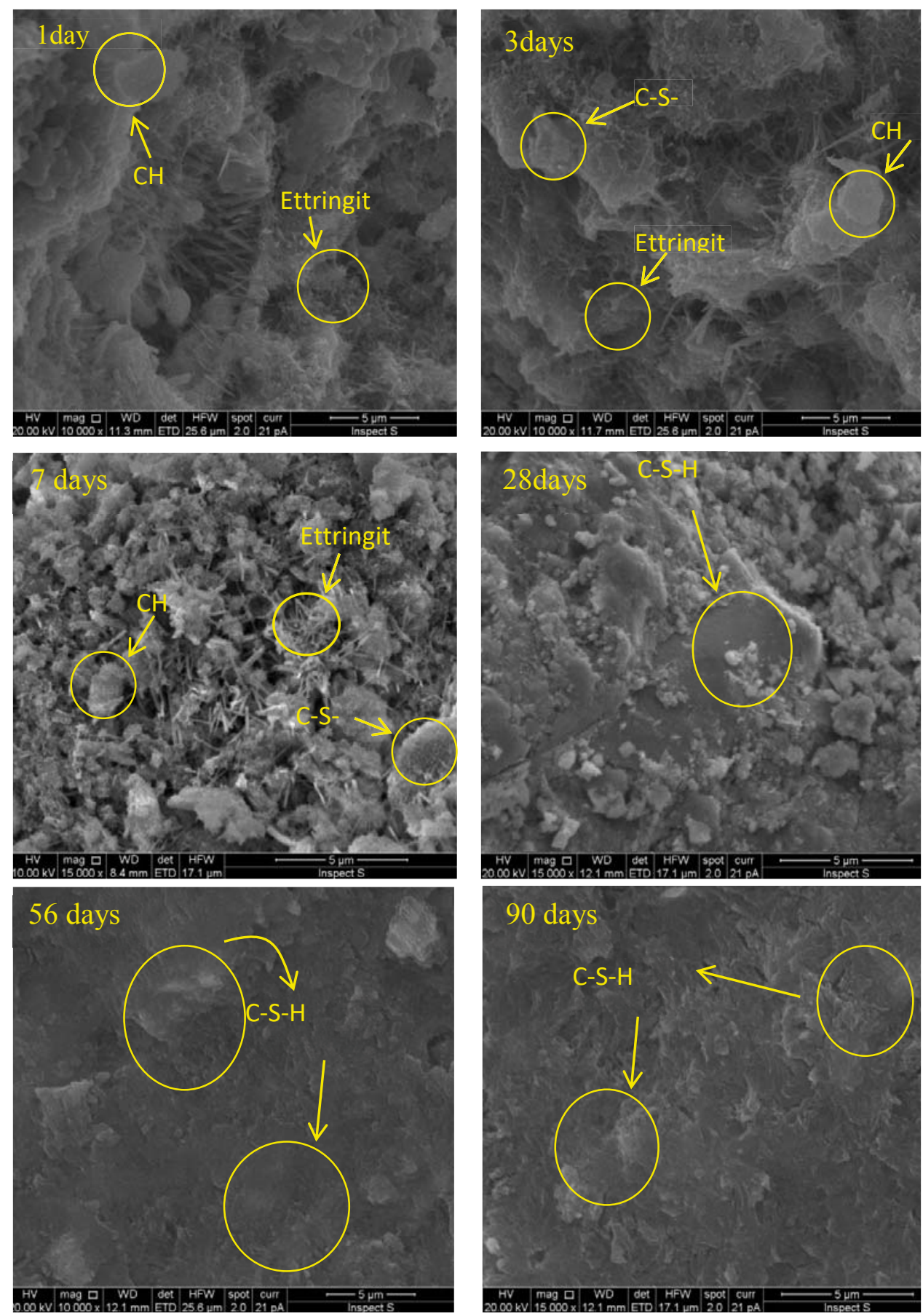

FIGURE 6. SEM microphotographs of binder paste containing 45\% cement replacement 
Furthermore, the first three mixtures got strength values close to that of RF specimen even in the long term curing.

- The SEM microscopic analysis results of $45 \%$ replacement binder showed that formation of needle like shape of Ettringite production and plate like shape of Portlandite formation at the short term curing (1-7 days). The formation of calcium silicate hydrate (C-S-H) can be observed at this age as well. At the medium and long term curing time, the images of SEM presented the only C-S-H formation and absence of $\mathrm{CH}$ and Etringite reflected dramatic changes in the microstructure of the hydrated paste of the tested binder along the time of curing. Moreover SEM images indicated that the C-S-H got more and more crystallisation over time.

- Finally, the outcomes of this study revealed that GGBFS and CKD can comfortably be used for cement replacement at levels between 45 and $60 \%$ with grantee results close to those that could be obtained from the conventional binder; cement.

\section{Acknowledgements}

Authors would like to express their gratitude to Liverpool John Moores University, Liverpool, UK for the laboratory support. Moreover, deep thanks from the authors to Hanson Heidelberg Cement Group, Skuthorpe, UK for providing the GGBFS samples used in this research.

\section{References}

Aïtcin, P.C. (2016). Supplementary cementitious materials and blended cements. In Science and Technology of Concrete Admixtures (pp. 53-73). Sawston: Woodhead Publishing.

Al-Zoubi, M.S. (2008). Undrained shear strength and swelling characteristics of cement treated soil. Jordan Journal of Civil Engineering, 2(1), 53-62.

Aprianti, E. (2017). A huge number of artificial waste material can be supplementary cementitious material (SCM) for concrete production - a review part II. Journal of Cleaner Production, 142, 4178-4194.

British Standard Institution [BSI] (1990a). Methods of test for soils for civil engineering purposes. Part 2: Classification tests (BS 1377-2:1990). London: British Standard Institution.

British Standard Institution [BSI] (1990b). Methods of test for soils for civil engineering purposes. Part 4: Compaction-related tests (BS 1377-4:1990). London: British Standard Institution.

British Standard Institution [BSI] (1990b). Methods of test for soils for civil engineering purposes. Part 7: Shear strength tests (total stress) (BS 1377-7:1990). London: British Standard Institution.

Eyo, E.U., Ng'ambi, S. \& Abbey, S.J. (2020). Performance of clay stabilized by cementitious materials and inclusion of zeolite/alkaline metals-based additive. Transportation Geotechnics, 23, 100330. https://doi.org/10.1016/ j.trgeo.2020.100330

Hayano, K., Dong, P.H. \& Morikawa, Y. (2013). Physical and mechanical properties of cement-treated granular soils with respect to geotechnical application. AIP Conference Proceedings, 1542(1), 301-304.

Hermawan, Marzuki, P.F., Abduh, M. \& Driejana, R. (2015). Identification of source factors of carbon dioxide $\left(\mathrm{CO}_{2}\right)$ emissions in concreting of reinforced concrete. Procedia Engineering, 125, 692-698. 
Higgins, D.D. (2005). Soil stabilisation with ground granulated blastfurnace slag. London: UK Cementitious Slag Makers Association (UK CSMA).

Jafer, H.M., Atherton, W., Ruddock, F. \& Loffill, E. (2017). The stabilization of a soft soil subgrade layer using a new sustainable binder produced from free-cement blending of waste materials fly ashes. In A. Loizos, I.L. Al-Qadi, T. Scarpas (eds.), Bearing Capacity of Roads, Railways and Airfields (pp. 1053-1060). London: CRC Press.

Jafer, H.M., Atherton, W., Sadique, M., Ruddock, F. \& Loffill, E. (2018a). Development of a new ternary blended cementitious binder produced from waste materials for use in soft soil stabilisation. Journal of Cleaner Production, 172, 516-528.

Jafer, H.M., Atherton, W., Sadique, M., Ruddock, F. \& Loffill, E. (2018b). Stabilisation of soft soil using binary blending of high calcium fly ash and palm oil fuel ash. Applied Clay Science, 152, 323-332.

Jha, A.K. \& Sivapullaiah, P.V. (2015). Mechanism of improvement in the strength and volume change behavior of lime stabilized soil. Engineering Geology, 198, 53-64.

Kunal, Siddique, R. \& Rajor, A. (2014). Strength and microstructure analysis of bacterial treated cement kiln dust mortar. Construction and Building Materials, 63, 49-55.

Ma, C., Chen, B. \& Chen, L. (2016). Effect of organic matter on strength development of self-compacting earth-based construction stabilized with cement-based composites. Construction and Building Materials, 123, 414-423.

Majdi, H.S., Shubbar, A.A.F., Nasr, M.S., Al-Khafaji, Z.S., Jafer, H., Abdulredha, M., Al Masoodi, Z., Sadique, M.M. \& Hashim, K.S. (2020). Experimental data on compressive strength and ultrasonic pulse velocity properties of sustainable mortar made with high content of GGBFS and CKD combinations. Data in Brief, 31, 1-11.

Oner, A. \& Akyuz, S. (2007). An experimental study on optimum usage of GGBS for the compressive strength of concrete. Cement and Concrete Composites, 29(6), 505-514.

Pourakbar, S., Asadi, A., Huat, B.B. \& Fasihnikoutalab, M.H. (2015). Stabilization of clayey soil using ultrafine palm oil fuel ash (POFA) and cement. Transportation Geotechnics, 3, 24-35.

Rahman, A. A., Abo-El-Enein, S.A., Aboul-Fetouh, M. \& Shehata, K. (2016). Characteristics of Portland blast-furnace slag cement containing cement kiln dust and active silica. Arabian Journal of Chemistry, 9, 138-143.

Ruijven, B.J., van, Vuuren, D.P., van, Boskaljon, W., Neelis, M.L., Saygin, D. \& Patel, M.K. (2016). Long-term model-based projections of energy use and $\mathrm{CO}_{2}$ emissions from the global steel and cement industries. Resources, Conservation and Recycling, 112, 15-36.

Sadique, M., Al-Nageim, H., Atherton, W., Seton, L. \& Dempster, N. (2013). Mechano-chemical activation of high-Ca fly ash by cement free blending and gypsum aided grinding. Construction and Building Materials, 43, 480-489.

Saride, S., Puppala, A.J. \& Chikyala, S.R. (2013). Swell-shrink and strength behaviors of lime and cement stabilized expansive organic clays. Applied Clay Science, 85, 39-45.

Shubbar, A.A., Jafer, H., Abdulredha, M., Al-Khafaji, Z.S., Nasr, M.S., Al Masoodi, Z. $\&$ Sadique, M. (2020). Properties of cement mortar incorporated high volume fraction of GGBFS and CKD from 1 day to 550 days. Journal of Building Engineering, 30, 101327. https://doi.org/10.1016/j.jobe.2020.101327

Wild, S., Kinuthia, J.M., Robinson, R.B. \& Humphreys, I. (1996). Effects of ground granulated blast furnace slag (GGBS) on the strength and swelling properties of lime-stabilized kaolinite in the presence of sulphates. Clay Minerals, 31(3), 423-433.

Zainab, S.A.K., Zainab, A. M., Jafer, H., Dulaimi, A.F. \& Atherton, W. (2018). The effect of using fluid catalytic cracking catalyst residue (FC3R) as a cement replacement in soft soil stabilisation. International Journal of Civil Engineering and Technology, 9(4), 522-533.

Zhao, J., Wang, D., Yan, P., Zhao, S. \& Zhang, D. (2016). Particle characteristics and hydration activity of ground granulated blast furnace slag powder containing industrial crude glycerol-based grinding aids. Construction and Building Materials, 104, 134-141. 


\section{Summary}

The development of an ecofriendly binder containing high volume of cement replacement by incorporating two by-product materials for the use in soil stabilization. The development of an ecofriendly binder containing high volume of cement replacement by incorporating two waste materials for the use in soil stabilization. This paper investigates the possibility of replacing ordinary Portland cement (OPC) by two waste and by-product materials for the use of a silty clay soil stabilization purpose. The soil was treated by $9.0 \%$ OPC where this mixture was used as a reference for all tests. Two by-product materials: ground granulated blast furnace slag and cement kiln dust were used as replacement materials. Consistency limits, compaction and unconfined compression strength $(U C S)$ tests were conducted. Scanning electron microscopy (SEM) analysis was carried out for the proposed binder to investigate the reaction of products over curing time. Seven curing periods were adopted for all mixtures; 1, 3, 7, 14, 28, 52, and 90 days. The results showed that the strength development over curing periods after ce- ment replacement up to $45-60 \%$ was closed to those of the reference specimens. The microphotographs of SEM analysis showed that the formation of Ettringite and Portladite as well as to calcium silicate hydrate gel was obvious at curing periods longer than 7 days reflected that the replacing materials succeed to produce the main products necessary for binder formation.

Authors' address:

Hassnen M. Jafer

(https://orcid.org/0000-0001-8740-9535)

Ibtehaj Jawad

(https://orcid.org/0000-0003-0940-9681)

Zaid Majeed

(https://orcid.org/0000-0002-5057-6003)

University of Babylon

College of Engineering

Department of Civil Engineering

Al-Hillah - Al-Najaf Road

Babylon, Iraq

e-mail: eng.hassnen.mosa@uobabylon.edu.iq

\section{Ali Shubbar}

(https://orcid.org/0000-0001-5609-1165)

Henry Cotton Building

15-21 Webster Street

Liverpool L3 2ET, UK 